\title{
A DIMENSÃO POLÍTICA DO SUJEITO NA CADEIA DISCURSIVA
}

\author{
(The subject's political dimension within \\ the discoursive chain)
}

\author{
Dionéia Motta Monte-Serrat ${ }^{1}$ \\ Leda Verdiani Tfouni ${ }^{2}$ \\ (Universidade de São Paulo - USP)
}

\begin{abstract}
The subject's political dimension within the discursive chain can be observed departing from the distinction between the concepts of discourse of the Law and juridic discourse. The first involves a ritual of overlapping turns of speech, in order to attribute cohesion and a unique sense to the event. The juridic discourse conceals this "speaking intersubjectivity" (Pêcheux, 1988) when it breaks the unity of meaning of the discourse of the Law and takes into account the subject as an effect of language, which is divided and opaque. Within this double dimension of the constitution of the subject, we suggest a distancing from the fetishism of the Law in order to bring the possibility to observe how both ideology and unconscious operate in the specific social formations that lead to the marginalization of subjects with low literacy degree (Tfouni, 2005).
\end{abstract}

Key-words: discourse of Law, juridic discourse, subjectivity, ideology, unconscious.

\section{RESUMO}

A dimensão política do sujeito na cadeia discursiva pode ser observada a partir da distinção entre os conceitos de discurso do Direito e de discurso jurídico. O primeiro comporta um ritual de superposição de falas para trazer uma situação enunciativa de coesão, de modo a dar-lhes um único

1. Doutoranda em Psicologia pela FFCLRP-USP, bolsista CAPES de estágio de doutorando no exterior, processo BEX 4394/10-0.

2. Professora Titular da FFCLRP-USP e pesquisadora do CNPq. 
sentido. O discurso jurídico dissimula essa "intersubjetividade falante" (Pêcheux, 1988) quando rompe com a unidade de sentido do discurso do Direito e leva em conta o sujeito como efeito da linguagem, dividido, opaco. Nessa dupla dimensão de constituição do sujeito, propomos um distanciamento do fetichismo do Direito para trazer a possibilidade de observar como operam a ideologia e o inconsciente nas formações sociais que levam à marginalização de sujeitos com baixo grau de letramento (Tfouni, 2005).

Palavras-chave: discurso do Direito, discurso jurídico, subjetividade, ideologia, inconsciente.

\section{Introdução}

A ideia de igualdade perante a Lei do discurso do Direito (Brasil, 1988: art. $5^{\circ}$ ) e a exigência de transparência da língua são tomadas como coisas corriqueiras, sem que percebamos que isso, ao mesmo tempo em que coloca a necessidade de intervenção de um "técnico" do Direito no que diz respeito às questões jurídicas, desvaloriza e marginaliza o discurso de sujeitos com baixo grau de letramento, embebido na subjetividade. Utilizamos as teorias do Letramento (Tfouni, 2005), da Análise do Discurso (AD) de Pêcheux (1988) e da psicanálise lacaniana (Lacan [1949]1998) para observar, de um lado, como o sentido passa por um percurso social ideológico e psíquico e, de outro, como as instituições impõem um sentido dominante com a finalidade de manter o status quo. Tomamos a língua como sujeita ao equívoco, como constituinte do sujeito em sua relação com o sentido — e o sentido como não único.

Questionamos a possibilidade de que seja ultrapassada a incompatibilidade existente entre o discurso jurídico - da enunciação durante uma audiência perante o Poder Judiciário - e o discurso do Direito - do enunciado, da lei, que determina todos os atos dessa audiência. Colocamos em questão o fato de que, quando o sujeito jurídico emerge em seu depoimento perante o juiz, há a produção de atos falhos, de lapsos, que se contrapõem às qualidades que regem o sujeito de direito. Equívocos na elaboração dos termos de audiência, 
fazendo descompassar o que foi falado e o que foi escrito revelam um sujeito jurídico constituído fora da "ciência régia" (Pêcheux, 2002).

A psicanálise lacaniana, articulada às teorias acima mencionadas, permitiu pensar a imagem controlada de sujeito de direito dando lugar a gestos do sujeito jurídico no espaço real. Situamos a Teoria Geral do Estado (Cintra, 1981) dentro do Estádio do espelho (Lacan [1949] 1998), para observar que a Lei (Estado) traça o caminho do desejo e aparece para o sujeito como imagem especular de sujeito de direito. No entanto, o sujeito que emerge no momento da enunciação confere um sentido particular ao seu enunciado. Embora entendamos que no sujeito de direito haja imposição de um sentido, há algo que rompe essa unidade e a modifica quebrando sua bidimensionalidade e traz à tona a dimensão do sujeito jurídico.

\section{O discurso do Direito como discurso do "dever ser"}

O evento da audiência, ocasião em que alguém faz seu depoimento perante o juiz de direito, é objeto de nosso estudo por estranharmos o fato de a língua, tida como "transparente", coexistir com a necessidade de intermediação do juiz nesses depoimentos. Qual seria a finalidade dessas intervenções? Seria a de evitar "ambigüidade", "distorção", "mal entendido"?

Ao tomarmos a audiência como um evento de letramento, podemos observar posições discursivas de sujeito influenciadas pela ideologia, como, por exemplo, o fato de só o juiz poder presidi-la; essa posição só está disponível para quem ingressa na carreira de magistrado. A função do juiz é a de aplicar a lei "igual para todos", mas, ao fazê-lo, fica instalado um lugar em que são ignoradas as desigualdades sociais, pois os que não têm acesso ao discurso do direito, técnico, ficam marginalizados.

A determinação da lei, sobre as intervenções do juiz nas falas em audiência e sobre a forma silogística pela qual ele deve elaborar sua decisão (sentença), traz à tona a dimensão jurídica da língua e sua 
efetividade social de uma maneira, digamos, exacerbada, diferente do juridismo ${ }^{3}$ que permeia as relações sociais de modo mais diluído.

Compreendemos o discurso do Direito (Brasil [1973], 2007) nesta pesquisa como algo que dá uma estrutura, um valor, tanto para a enunciação do depoente (introduz um efeito jurídico aos enunciados transcritos para o termo); como, para a sentença (só lhe concede valor jurídico se atender aos requisitos legais do raciocínio silogístico). O discurso do Direito determina os direitos e deveres dos depoentes e do juiz, ignorando o discurso jurídico com seus atos falhos e lapsos.

O discurso jurídico, por sua vez, não está presente só no ambiente forense, mas o ultrapassa e envolve a questão da constituição do sentido dos enunciados e discursos, valorizando o agir (Lagazzi, 1988:20). Essa percepção trouxe a diferenciação, da que falaremos mais adiante, entre as noções de sujeito de direito, sujeito do direito e sujeito jurídico, ainda não desenvolvidas em literatura especializada.

As teorias do Letramento (Tfouni, 1992, 2005) e da AD pêcheutiana (Pêcheux, 1988) trouxeram nova maneira de compreender o que se passa na instância jurídica, uma ordem de sentidos que constitui a memória do dizer, determina as relações sociais. Trata-se de uma ordem do "dever ser", que traz noções de obrigação e de imperativo que trabalham a materialidade da língua e a origem do dizer de sujeitos fora de um lugar de livre escolha, sob o controle da lei (Cintra, 1981:7). É possível observar uma irreversibilidade pré-determinada nos papéis assumidos em seus discursos (pelos sujeitos inseridos nesse contexto), constitutiva do sentido e que dá autoridade ao juiz para interpretar o que o autor ou o réu diz e transferir isso para documento escrito. Essa competência, que a lei dá ao juiz, de fazer recortes evitando "ambigüidade", "distorção", "mal entendido" (Silva, 1987:145), nos causou estranhamento, pois não seria necessária se de fato considerarmos as características de imutabilidade e transparência supostamente existentes na língua.

3. O termo "juridismo" implica relações interpessoais marcadas por relações de poder (Lagazzi, 1987). 
O momento do depoimento oral do autor e do réu, perante o magistrado, faz parte da constituição do sentido daquilo que enunciam e, por esse motivo, é nosso ponto de partida para observar a determinação e o assujeitamento pela lei. Nossa pesquisa pretende contribuir com a compreensão de que os discursos não são neutros, e de que o contexto faz parte desses discursos determinando os sentidos. Pretendemos observar o que se pode empreender do sujeito jurídico e os efeitos que isso produz sobre sua estruturação em contraposição à estrutura rígida trazida pelo sujeito de direito, sendo que esta última tem poder formador sobre o sujeito jurídico discordante. Sob o aspecto científico e não mais tomando a relação entre Direito e sociedade de maneira estanque, sentimo-nos incomodadas a refletir sobre o sujeito determinado e assujeitado pelo jurídico de um lado, em confronto com o real e o papel da história, de outro, que permitem diferentes respostas do sujeito a essa determinação.

\section{Relações de poder e materialidade discursiva}

A fim de que haja melhor compreensão sobre a relação entre juiz, autor e réu, contexto de onde foi coletado material para esta pesquisa, abordaremos o conceito de poder e seus efeitos sobre o sujeito; as relações de poder em que se insere este último; e, por fim, como tudo isso se materializa no discurso, como o sujeito é afetado pela lei e reproduz isso no seu falar.

O discurso do Direito (entendido aqui como o conjunto de determinações da lei a respeito dos atos da audiência), que, segundo a visão dos juristas seria "neutro", não é tomado como base para a análise dos dados desta pesquisa. Nosso foco está no funcionamento do discurso jurídico durante as falas dos depoentes, que se dão no ambiente forense, formal, permeado da ideologia da coerção, segundo procedimento imposto pela lei (discurso do Direito), Código de Processo Civil (CPC) (Brasil, [1973] 2007) e dirigidas pelo juiz.

Antes de nos aprofundarmos em alguns conceitos da Teoria do Letramento (Tfouni, 1992, 2005) e da AD (Pêcheux,1988, 1990 e 
2002) para estabelecermos a diferença entre o discurso do Direito e o discurso jurídico, procuraremos esclarecer, de modo breve, como se desenvolveu o processo histórico das relações coercitivas do Estado em relação ao indivíduo, levando à emergência do sujeito de direito.

A noção de discurso do Direito se distancia da noção de discurso jurídico. Enquanto este último é entendido como a aplicação formal da Lei em contextos institucionalizados (relações interpessoais marcadas por relações de poder inscritas numa esfera de tensão denominada juridismo) (Lagazzi, 1987), o discurso do Direito (Brasil, [1973], 2007) é compreendido como algo que determina como se dá uma audiência, quais são os poderes e os deveres do juiz e das partes. $\mathrm{O}$ discurso do Direito é, então, o nosso ponto de partida na percepção dos sentidos que circulam no discurso científico e supostamente neutro; e o fato de ele abranger um campo amplo de relações humanas nos levou a restringir a pesquisa a alguns aspectos da Teoria Geral do Processo (Cintra, 1981), pequena parte da Teoria Geral do Estado.

Sem nos distanciarmos do foco de estudo sobre o discurso jurídico, nos restringiremos aos efeitos de sentido que circulam dentro da instituição do Estado, denominada Poder Judiciário, e, mais especificamente, dentro do funcionamento de uma audiência em que o cidadão comum vai reclamar, à pessoa investida do poder estatal (juiz), seus direitos e pedir uma solução. Não será feita análise de conteúdo das falas ou das sentenças do juiz de direito. Como a AD, o Letramento e a psicanálise lacaniana adotam a postura científica do dado indiciário (Ginzburg, 1989) e lidam com o conhecimento opaco dos dados, colocamos em relevo o contexto (e não o conteúdo) em que foram produzidas essas falas e sentenças (Tfouni, 1992), de modo a obtermos uma contribuição teórica essencial para discernir o discurso jurídico: o advento do paradigma indiciário para as ciências humanas, por elas trazido, torna possível o vislumbre do paradoxo de um sujeito "livre para se obrigar".

A compreensão de como se dá o funcionamento de uma audiência é importante para entender o discurso do Direito (Brasil, [1973], 2007) com suas restrições, como, por exemplo, a utilização obrigatória do Poder Judiciário para resolver conflitos (por meio de 
um instrumento chamado processo, com várias fases e, entre elas, a fase da audiência); o fato de o depoimento prestado não ser um ato espontâneo, mas um dever a ser realizado com dia e hora marcados. As audiências e as sentenças elaboradas por juízes de direito, que formam o corpus de nossa pesquisa, expressam uma parte do funcionamento do Poder Judiciário, situam-se dentro do que se chama de "Teoria Geral do Processo" (Cintra, 1981), que, por sua vez, constitui uma parte da Teoria Geral do Estado. São “naturais”, para a Teoria Geral do Processo afirmações como: o Estado impõe-se sobre os particulares autoritariamente; o processo é instrumento do Estado para prestar a jurisdição e tem, como finalidade, estabelecer o que determina a lei, e não solucionar o conflito entre as partes; o juiz, como destinatário das provas feitas no processo, deve analisar a relevância e pertinência delas e proferir sua sentença final sendo-lhe vedada a decisão pelo conhecimento próprio dos fatos em litígio.

Essa pequena amostra do conteúdo do discurso do Direito o traz como uma ciência que se diz neutra, apagando as origens históricas de suas imposições. As teorias do Letramento (Tfouni, 2005) e da AD (Pêcheux, 1988) trouxeram a possibilidade de utilizarmos essas mesmas origens históricas para buscar o modo como se constituem os sentidos no jurídico, ou seja, para buscar enxergar a ciência do Direito para além da ideia de transparência e de idealismo jurídico. Assim, sob uma perspectiva epistemológica compreendemos o Direito como modo de produção de um funcionamento social que reproduz o Estado, e, ao mesmo tempo, quer ser visto desvinculado dos fenômenos sociais.

É a materialidade discursiva associada à visão crítica sobre o discurso do Direito (Miaille, 1979; Tfouni, 2005; Pêcheux, 1988, Haroche, 1992), que nos permite observar a perda de unidimensionalidade deste último, sua suposta neutralidade, expondo o fosso existente entre a teoria jurídica e sua prática. A coação inerente às normas traz a impressão de transparência, transforma-se num obstáculo que faz o foco sair da realidade e ir para as ideias (Miaille, 1979). Distanciando-nos desse ponto de vista, conforme será demonstrado mais adiante, podemos pensar a materialidade discursiva das falas em audiência realizadas pelo Poder Judiciário como um lugar 
onde se observa o sujeito cindido, ou seja, aquele que ocupa a posiçãosujeito de direito ("aquele que é para a lei”) (Haroche, 1992) e o que ocupa a posição-sujeito jurídico (aquele que emerge no discurso jurídico, com características discordantes da estrutura rígida que dá forma ao sujeito de direito). Embora a ciência jurídica positiva se faça "neutra" ao conceituar Estado, juiz, justiça sob um proceder objetivo, trazendo a ideia de que está fora de um contexto social em que tudo parece se equivaler, deve ser observada sob o ponto de vista de sua materialidade histórica, como um produto da sociedade integrado à estrutura econômica, como tendo uma "causalidade estrutural" (Miaille, 1979:74)

\section{Sujeito de direito, sujeito do direito e sujeito jurídico}

Com essa visão do contexto sócio-histórico sobre a origem da ciência do Direito é possível compreender o caráter artificial da noção de sujeito de direito, pois, juntamente com a noção de Estado, representam "formas jurídicas necessárias" a uma sociedade capitalista (Miaille, 1979:107). Para funcionar, o capitalismo supõe a "atomização", a "representação ideológica da sociedade como um conjunto de indivíduos separados e livres” (Miaille, 1979:111), fenômeno compreendido aqui sob o conceito de sujeito de direito. $\mathrm{Na}$ categoria sujeito de direito, levando em conta o contexto sóciohistórico, é possível perceber que não existe liberdade, nem igualdade, e que o Estado ocupa o pilar do sistema jurídico, sob a forma sociopolítica dentro da qual a classe dominante exerce o seu poder (op. cit.:128). Segundo ensina Miaille (1979:132), só poderemos compreender Estado e sujeito de direito quando os tomarmos como conceitos históricos: nascidos em determinada sociedade, num momento determinado e com uma função determinada.

Podemos afirmar, então, que o sistema jurídico reproduz o Estado e o sujeito de direito. Para questioná-los é preciso deslocá-los da lógica jurídica e submetê-los ao corte epistemológico, enxergar a lógica jurídica como algo que divorcia direito e fatos (Pêcheux, 1988:196; 
Miaille, 1979:170). A relação econômica depende da relação política e social. A formação social não é um lugar de justaposição, mas de uma unidade, mesmo que contraditória (Miaille, 1979:198). O Direito, por ter hegemonia no sistema de comunicação capitalista, traz, na norma, a ideia de "troca equivalente" e, sendo marcado pelo idealismo, esconde, sob as "relações livres e iguais", a relação entre proprietário do capital e proprietário da força de trabalho (op. cit.).

Tomado como "forma plenamente visível da autonomia" (Pêcheux, 1988), o sujeito de direito, também compreendido como "forma-sujeito" (op. cit.), tem sua vontade ligada não apenas a uma "orientação da pessoa em direção da ação", mas também a uma "valorização do agir" (Lagazzi, 1988:20). Seu significado é o de alguém que é "submetido à autoridade soberana", "que é subordinado" (Haroche, 1992:158). A ideia do sujeito de direito, portanto, implica um só discurso possível, onde não há lugar para "fazer valer um desejo próprio" (Legendre apud Haroche, 1992:158). O discurso do Direito obscurece, sob a suposta transparência da linguagem, o "caráter material do sentido das palavras e dos enunciados" (Pêcheux, 1988:160). Isso ocorre porque, segundo ensina Pêcheux (apud Guimarães 2002, p. 14), o sujeito fala de um lugar no interdiscurso em que a memória é estruturada pelo esquecimento de que já significa.

Sujeito de direito é a "identificação pela qual o sujeito 'se reconhece' como homem", processo em que "o imaginário [...] mascara radicalmente qualquer descontinuidade epistemológica" (Pêcheux, 1988:128). Situa-se nas categorias ideologia e inconsciente a que Pêcheux (1988:152) dá o nome de "estruturas-funcionamento".

Utilizamos a teoria psicanalítica lacaniana (Lacan, 1992:342) para situar a noção de sujeito de direito, neste estudo, como signo imagem de ' $a$ ', que nos permite compreender o Estado, como grande Outro, na constituição do sujeito. Voltaremos a esse tema mais adiante.

A partir do conceito de sujeito de direito sentimos a necessidade de estabelecer uma diferenciação com o conceito de sujeito do direito que, nesta pesquisa, é aquele cuja vontade é disciplinada pela lei (Miaille, 1979:137). Este último se apóia, paradoxalmente, no rigor do texto da lei e nas supostas "liberdade" e "autonomia" para decidir 
sobre suas ações. Sujeito do direito é, neste estudo, o sujeito que ocupa a posição discursiva de juiz de direito dentro de determinada sociedade e desempenha uma função determinada, em que a transmissão de sua vontade é prevista e organizada pela lei (Miaille 1979:132 e 137). É aquele que, na burocracia "procede dos escritos da lei, e não tem nada a dizer que lhe seja próprio"; aquele cujo desejo é mantido como "legal satisfação" (Legendre 1976, apud Haroche, 1992:190). Sujeito do direito é aquele que tem "competência jurídica”, que faz um trabalho de construção que, mediante uma seleção das propriedades pertinentes, permite reduzir a realidade à sua definição jurídica, essa “ficção eficaz" (Bourdieu, 1998:233).

Diante desse refinamento de conceitos acrescentamos, em nosso estudo sobre a dimensão política do sujeito na cadeia discursiva, o conceito de sujeito jurídico, entendido como diverso dos conceitos de sujeito de direito e de sujeito do direito, diferença, até onde sabemos, ainda não desenvolvida pelos estudiosos do assunto. O sujeito jurídico corresponde ao funcionamento da estrutura discursiva a que Pêcheux (1988:163-164 e 183) denomina "forma-sujeito". Sob esse funcionamento, o sujeito jurídico não reconhece sua subordinação, seu assujeitamento ao Outro (Estado), pois se assujeita sob a forma da autonomia. O sujeito jurídico é constituído sob os efeitos de sentido que circulam no contexto da audiência, em que a lei dita o que deve ou não deve ser feito, o que pode e o que não pode ser dito.

\section{A dimensão política do sujeito na cadeia discursiva}

Estabelecidas as diferenças conceituais entre sujeito de direito, sujeito do direito e sujeito jurídico, utilizamos o continuum desenvolvido por Tfouni (1992) para observar, na cadeia do discurso jurídico, a posição-sujeito do direito (ocupada pelo juiz de direito) em lugar diferente da posição-sujeito jurídico (ocupada pelos depoentes de nosso corpus). Lembramos que o fato de conceituarmos sujeito de direito como ideológico nos leva a ligá-lo ao discurso do Direito, do enunciado, da lei, lugar diverso do discurso jurídico, da enunciação. 
Assim como o discurso do Direito se mostra como transparente e universal, o sujeito de direito corresponde com as características de unidade e indivisibilidade. Já o discurso jurídico com sua materialidade discursiva traz consigo o sujeito jurídico, opaco e discordante.

Para melhor compreensão dessa diferença conceitual trazemos para a cena a audiência realizada pelo Poder Judiciário a visão de Tfouni (1992) sobre o Letramento, prática social, processo sócio-histórico que agrupa tanto alfabetizados com variados graus de domínio da escrita, quanto os não-alfabetizados. Com essa visão é possível perceber que as práticas sociais da escrita dentro da audiência têm maior eficácia quanto maior for o grau de letramento do indivíduo. Tfouni (1992:26) exemplifica sua teoria propondo o continuum abaixo, uma linha imaginária onde estariam as várias posições discursivas disponíveis em uma sociedade letrada, sendo que essas posições são colocadas, pela autora, como determinantes do grau de letramento dos sujeitos ${ }^{4}$ :

\begin{tabular}{|rr|}
\hline $\begin{array}{l}\text { iletrados não sofrem } \\
\text { influência da escrita }\end{array}$ & letramento \\
\hline menos letrado & mais letrado \\
& \\
& alfabetizados \\
\hline
\end{tabular}

Segundo Tfouni (1994:61), a prática da escrita traz consigo uma dominação cultural, estabelecida principalmente com base na 'força', no 'poder' e na 'autoridade' dessa mesma prática. Assim, o discurso do Direito pressupõe uma autoridade de imposição de quem o produz, se caracteriza por ser monológico, ou seja, por não admitir múltiplas leituras (Tfouni, 1992:35); localiza-se, na linha do continuum, nos níveis mais abstratos e sofisticados de uso da escrita. Como linguagem

4. Existe letramento sem alfabetização. 
técnica e oficial (Tfouni, 2007:155) cria uma "barreira linguística” em que se encobre a ordem "igualar para melhor dominar".

A atuação do juiz de direito no procedimento judicial da audiência é incompatível com sua liberdade de conduta, pois não atua para defender interesses próprios e o poder que exerce não é seu, mas o do Estado (Dinamarco, 2000: 478). O controle dos sentidos que circulam no contexto da audiência é dado, pela lei, ao juiz. É ele que faz os recortes das falas e faz o ditado do que ouviu para o escrivão. Tem a incumbência, não explícita, de administrar a produção e circulação dos sentidos para formar o "consenso". Essas medidas não têm sua origem no juiz, mas na lei, que se faz cumprir por meio do Poder Judiciário, uma instituição do Estado. Desse modo é criada uma ilusão do mundo como "semanticamente estabilizado" (Pêcheux, 2002), um lugar onde todos parecem pensar e agir de igual modo. Fica naturalizada, então, a função do juiz de "corrigir" esses depoimentos, como ensinam os juristas (Silva,1987:145): "A obscuridade indica falta de clareza. E o juiz a remove, suprindo a deficiência".

Para compreendermos como se dá o discurso do Direito é necessário observar o funcionamento da lógica jurídica segundo a visão sócio-histórica de que já falamos. A lógica jurídica é comparada, por Miaille (1979:170), ao funcionamento da gramática, pois apresenta uma abstração de conteúdo em favor da forma, a fim de que o pensamento seja coerente; ela vai além da gramática, pois ao constituir o pensamento, constrói alguns conceitos que eliminam o conteúdo concreto para o qual remete. A lógica jurídica reúne termos, classifica-os de modo a construir uma unidade para o sistema jurídico. O discurso do Direito, portanto, ao funcionar dentro da lógica jurídica, exclui contradições, leva ao controle dos sentidos por meio de uma ideologia dominante, produz uma voz social homogênea. Ao priorizar uma linguagem "transparente", com um só sentido, ele produz "discursos monologizantes, totalizantes, 'científicos', 'descentrados”" (Tfouni, 1992:100). Ressaltamos que isso se dá dentro de práticas e de instituições sociais onde há imposição do sentido; este se materializa em práticas discursivas que, por sua vez, irão determinar as posições de sujeito, posições discursivas que não estão disponíveis para todos (op.cit). 


\section{Sujeito de direito $\mathrm{X}$ sujeito jurídico}

Quando nos propusemos a relacionar as falas (realizadas durante audiência e transcritas) com o termo de audiência (contém ditado do juiz a respeito do que ouviu), para estudar a "necessidade" dos recortes, feitos pelo magistrado, ficamos intrigadas com os modos de produção do sentido e do sujeito. Conforme já mencionamos anteriormente, as teorias do Letramento (Tfouni, 2005), da AD (Pêcheux, 1988) e da psicanálise lacaniana permitem que observemos a relação sujeito-grande Outro, no corpus, para além do "achar" do pesquisador, pois relacionam o discurso, efeito de sentidos, de recortes desse corpus, com o exterior da língua, até chegar à compreensão do processo de produção do discurso jurídico.

Os sujeitos deste estudo ocupam posição discursiva alocada pela lei (autor, réu, juiz, escrevente de sala) no contexto de audiência em Vara Cível da Justiça Estadual; formações discursivas determinadas pelo jurídico os influenciam naquilo que podem ou devem dizer. As falas partem da lei, são disciplinadas pela lei e a ela retornam. Nesse momento é importante lembrar que a constituição do sujeito se dá no campo da linguagem, o que permite nosso estudo sobre o assujeitamento dos sujeitos. A cena da audiência é tomada como condição de produção do discurso jurídico, de produção das enunciações, influenciando efeitos de sentido do dizer. Ao enunciar, o sujeito depoente ou o sujeito que ocupa a posição de juiz se constitui em sujeito do discurso e é assujeitado pelas circunstâncias de sua enunciação. Os sentidos que circulam numa audiência do Poder Judiciário são determinados pela ideologia (Pêcheux, 1988) inerente a esse Poder e pela constituição psicanalítica do sujeito (Lacan [1949][1960]1998; [1953-1954]1986; [1954-1955]1987; 1992, [1957]1998).

As falas realizadas durante audiência em Vara Cível do Poder Judiciário estadual são influenciadas pelo contexto sócio-histórico e ideológico de uma instituição do Estado, o Poder Judiciário. Isso compreende um não-dito que impede que se faça justiça pelas próprias mãos; que leva o sujeito à prática de uma série de atos regulados por lei disciplinadora do procedimento judicial; que organiza práticas e 
ritos que se refletem na prática discursiva (a lei prevê o que pode e o que não pode ser dito ou escrito).

É esse o contexto por nós escolhido para melhor estabelecer as diferenças entre sujeito jurídico e sujeito de direito. Durante a coleta de dados para a análise, utilizamos um gravador para registrar as falas em audiência. Estas foram transcritas posteriormente, a fim de serem comparadas aos termos ditados pelo juiz, digitados pelo escrevente de sala. Esse material constitui a superfície linguística, lugar de onde iniciamos nosso estudo da "dupla ilusão" (Pêcheux, 1988) do sujeito, para estranhar o fato de que o sujeito teria autonomia e consciência de seu discurso, ou de que aquilo que diz corresponderia exatamente ao que pensa, ignorando que há um discurso preexistente ao seu, o discurso da lei.

Se levarmos em conta o ponto de vista da $\mathrm{AD}$ e do Letramento, o sujeito não nasce nem se desenvolve, mas se constitui, e essa constituição abarca, também, o sujeito do inconsciente articulada ao plano social (Elia, 2004:36). A noção de sujeito, para a teoria psicanalítica, é a de que ele é "ato de resposta" (op. cit.:41) ao grande Outro, e esse encontro entre sujeito e Outro "cria o passado" que passa a atuar como "anterioridade determinante" (op. cit.: 43-44). A articulação da visão psicanalítica na relação entre sujeito e Estado se faz necessária nesta pesquisa, pois, "o fato de que haja língua tem a ver com o fato de que haja inconsciente" (Milner, 1987:42) (v. "sujeito político e psicanálise" mais adiante).

O confronto entre sujeito de direito e sujeito jurídico, dentro do que já afirmamos até aqui, nos permite dizer, resumidamente, que: o discurso do Direito, "fornece-impõe" a realidade, e, juntamente com ela, o seu "sentido" (Pêcheux, 1988:164), fornece a imagem do sujeito de direito. Fica dissipada, dentro do discurso jurídico, a evidência da transparência de linguagem do discurso do Direito, aquilo "que é" e "o que deve ser" do sujeito de direito, pois no discurso jurídico emerge o sujeito jurídico, assujeitado, num "jogo de efeitos ideológicos" (Pêcheux, 1988:153), presente em todo discurso, assujeitado aos efeitos de sentido sob a "forma plenamente visivel da autonomia" (Pêcheux, 1988:159). O modo de ser da "ciência régia" (Pêcheux, 
2002) do Direito, a que denominamos discurso do Direito, encobre o caráter material do sentido das palavras e dos enunciados (Pêcheux, 1988:160), constituindo, sob esse funcionamento de "evidência" e de "autonomia”, o sujeito jurídico.

O estranhamento sobre a "estabilidade" e a "transparência" da escrita (Tfouni, 1992, 2005; Pêcheux, 1988), nos levou a comparar as falas gravadas e transcritas com o conteúdo delas fixado no "termo de audiência". Observamos a função do juiz (sujeito do direito) em sua função de remover "obscuridades" e "suprir deficiências", na crença de que existe uma língua universal, homogênea, que igualaria a todos perante a lei. A imposição de padrões de dizer e fazer, na audiência, levou ao surgimento de atos falhos, lapsos do sujeito jurídico, da enunciação. Observamos que existe "uma tensão constante entre alíngua e língua" (Tfouni 2007) e que os atos falhos são "momentos mal sucedidos" nessa tensão (Tfouni, 2008). Procuramos atentar para alguns fatos lingüístico-enunciativos que, desprezados pelo sistema jurídico, tornam-se relevantes, e evidenciam, ao contrário do que estabelece o Direito (língua transparente e o sujeito mensurável e predizível), que a língua é opaca e o sujeito, falho (Tfouni, 1992, 2005; Pêcheux, 1988; Lacan [1949][1960]1998; [1953-1954]1986; [1954-1955]1987; 1992; [1957]1998).

\section{Sujeito político e psicanálise}

O fato de Lacan, em sua obra, destacar, além da dimensão social e lógica do grande Outro, sua dimensão política (Zarka, 2004:129) instigou-nos a utilizar a teoria psicanalítica no estudo sobre o sujeito político. Isso nos levou a propor o estudo da relação entre o Estado e a constituição do sujeito jurídico a partir do texto "o estádio do espelho" de Lacan ([1949]1998), em que a constituição do sujeito se dá a partir da imagem especular; em que o estatuto do objeto do olhar é o de causador do sujeito. Com esse pressuposto podemos compreender que, na imagem especular, o sujeito se vê como o outro vê. Algo do funcionamento do sujeito fica recalcado devido a uma 
"necessidade" de não contradição no que diz respeito ao "amor ao Estado" (Orlandi, 1996).

Para observar a relação entre sujeito e Estado sob a ótica de Lacan lembramos a imagem especular supõe um aparato que condiciona sua constituição (Melenotte, 2006). Associamos esse aparato (Lacan [1949]1998) à relação Estado-sujeito, relação em que o grande Outro (Estado) ocupa a posição de espelho "A", lugar a partir do qual o discurso se constitui. Assim como no estádio do espelho nem a imagem do corpo, nem o corpo "próprio" possuem individualidades prévias (por ser esse episódio constitutivo), podemos afirmar que o sujeito não preexiste ao Estado. Por ser uma anterioridade determinante do sujeito, o Estado, como o grande Outro em relação ao sujeito, tem, além da dimensão social e lógica, a dimensão política. Assim, o eu se reconhece no Outro (Estado). O referencial especular, por não ser da ordem visual, tem origem no fato de que o sujeito é objeto do olhar do outro; a unidade dada ao sujeito não é da ordem de sua própria percepção, é dada de fora, é simbólica. A teoria da psicanálise lacaniana pressupõe uma relação de dependência entre meio e indivíduo. Com essa compreensão, podemos afirmar que a relação sujeito-Estado (Outro) não é "contratual” como preconiza o Direito (Teoria Geral do Estado), quando afirma que haveria um "contrato" entre os homens e o Estado para que este último lhes dê proteção.

Segundo o discurso do Direito, na visão dos juristas, a unidade do Estado tem origem em sua autoridade soberana. Conforme afirmamos anteriormente, da noção de Estado surge a noção sujeito de direito, que é aquele "submetido à autoridade soberana", aquele que é para a Lei (Haroche, 1992). Para compreender, então, que a relação sujeito-Estado não é contratual e para descrever o modo como se dá a constituição desse sujeito de direito, adaptamos aqui a teoria materialista dos processos discursivos de Pêcheux (1988). Segundo esse autor (op. cit.), o discurso do Direito, e o Poder Judiciário (Aparelho Ideológico do Estado) estabelecem a ideologia dominante, ao materializar as relações entre o juiz e os depoentes. Produzem um "tecido de evidências subjetivas" em que se constitui o sujeito e, ao mesmo tempo, dissimula essas relações (pela própria ideologia e pelo 
inconsciente) através dos dois esquecimentos: o sujeito se constitui a partir do esquecimento daquilo que o determina (a lei), quando se identifica com uma formação discursiva dominante e reinscreve, em seu próprio discurso, elementos do "já dito", que "fornece-impõe a 'realidade' e seu sentido" (Pêcheux, 1988).

É na linguagem que o sujeito se constitui, o que nos leva a articular à relação sujeito-Estado a visão psicanalítica do sujeito do inconsciente (Freud, 1996; Lacan [1949][1960]1998; [19531954]1986; [1954-1955]1987; 1992; [1957]1998). Desse modo, os conceitos de necessidade, demanda e desejo na experiência do sujeito jurídico, situado dentro do discurso jurídico, o tornam sujeito do "desejo do desejo do Outro" (Dor, 1989). Quando o sujeito busca o Estado para a solução de um conflito, este (Estado) se inscreve, em relação a ele (sujeito), como um sujeito privilegiado (Outro) e o assujeita ao universo de seus próprios significantes. Há uma inadequação entre a justiça desejada pelo sujeito-depoente e o que se faz ouvir desse desejo na demanda. O desejo do sujeito-depoente fica como "falta a ser para além da demanda" e o inscreve numa relação indestrutível com o desejo do Outro (Estado) (Dor, 1989).

Existe uma dificuldade, ao tratarmos da relação sujeito-Estado, situada na ligação entre ideologia e inconsciente, o que complica a compreensão das "estruturas-funcionamento" (Pêcheux, 1988), que dissimulam sua própria existência na constituição do sujeito. A interpelação vincula aparelho repressivo e aparelho ideológico de Estado, vincula sujeito de direito e sujeito ideológico, mostrando que existe algo que fala ao sujeito, antes que ele possa dizer: "Eu falo" (Pêcheux, 1988). No interdiscurso, além do efeito de encadeamento do pré-construído, há a constituição do sujeito em sua relação com o sentido (articulação) (Pêcheux, 1988). A transparência e a linearidade da língua trazem imperativos do poder jurídico: o Estado impõe "como" e "quando" falar, o que justificaria os recortes do juiz nas falas e o formato silogístico para as sentenças que este elabora.

$\mathrm{Na}$ inscrição do Estado junto ao sujeito (pequeno outro), como outro privilegiado (grande Outro), a liberdade de escolha e a autonomia do sujeito-depoente estão no "signo imagem de a" (Lacan, 1992), 
na imagem de sujeito de direito oferecida pelo Estado (Outro), na posição de espelho "A", do esquema ótico de Lacan ([1960] 1998). O assujeitamento do sujeito lingüístico e jurídico se dá a partir dessa imagem. O ideal do eu, ou seja, a imagem de sujeito de direito, é uma introjeção simbólica (Lacan, 1992). A Lei, ao determinar "como" e "quando" falar durante uma audiência perante o juiz, traça o caminho do desejo do sujeito. Desse modo o Estado tem função essencial na determinação do sujeito, aparecendo, para este, como "signo imagem de $a$ ”, imagem especular desejável, que fala antes de o sujeito falar, situação que será exemplificada em seguida, com dados colhidos em audiência.

\section{A enunciação e a constituição do sujeito político na cadeia discursiva}

Quando falamos em discurso do Direito precisamos levar em conta a percepção do não-dito, originado na ficção jurídica, de que o indivíduo não desconhece a lei: "ninguém se escusa de cumprir a lei, alegando que não a conhece” (Brasil [1942]2007: art. 3). Essa pressuposição não pode ser ignorada e tem um lugar importante na materialidade linguística dos sujeitos estudados durante uma audiência perante o Poder Judiciário. É a lei que determina os ritos dos atos jurídicos realizados nessa audiência; estabelece-os por meio de princípios da Teoria Geral do Processo (Cintra, 1981). É, portanto, a lei que, de maneira pormenorizada, estabelece quem fala, o quê fala, quando fala (Brasil [1973] 2007, arts. 346, 445-446, 451 e 457); ela organiza os atos de fala dos sujeitos-depoentes. Assim, os ritos impostos ao procedimento jurídico da audiência atuam ideologicamente, de modo que o depoente se submeta a eles sem que o fato de que seu desconhecimento desses mesmos ritos the cause estranheza. A estrutura do discurso do Direito determina previamente valores para as enunciações, introduz valor jurídico nas relações entre o juiz e os depoentes aos quais estes se submetem "livremente".

Os atos de enunciação, tanto do juiz, quanto dos depoentes, estão, portanto, relacionados a algo que está além deles, ou seja, à 
lei, que dita quais são seus deveres e direitos numa audiência, a fim de orientar o sentido das falas em determinada direção. No Código de Processo Civil (CPC) ([1973]2007) - lei que regula os atos do procedimento judicial - o discurso do Direito se coloca como começo, origem das falas em audiência, determinando, para esse contexto, um sentido prévio $^{5}$. Um dos meios pelos quais a lei regula o encadeamento das falas é concedendo ao juiz o poder de interrogar, já que a ele cabe "dirigir os trabalhos da audiência" (op. cit.: art. 446). Vejamos, no recorte abaixo, em que o juiz (J) interroga o sujeito-depoente (TA) e este, ao responder, mostra-se disperso em sua fala, mas, posteriormente, no texto escrito do termo de audiência, torna-se coerente e conciso:

\section{$\mathrm{J}: \mathrm{O}$ que que a senhora sabe?}

TA: É que ele morou lá um ano ... um ano de:: ... sem pagar aluguel sem pagar condomínio e que foi movida uma ação de despejo contra ele e ele saiu deixou danos no imóvel

J: Que ... que danos foram esses?

TA: Pintura geral do imóvel limpeza controle que ele entregou ... ele entregou a chave ao do ... à doutora $(\mathrm{V})$ a advogada ... ao doutor $(\mathrm{X})$ no escritório dele ... aí o controle não funcionava ... limpeza geral ... pintura geral no imóvel ...

Essas falas gravadas e transcritas correspondem ao seguinte recorte do termo de audiência:

Inquirida pelo MM. Juiz, na forma e sob advogado da autora, respondeu: Foi a depoente quem fez a vistoria de entrada e saída do imóvel. Lembrase que o imóvel não foi devolvido nas mesmas condições em que foi locado, já que o locatário não fez a pintura geral nem a limpeza [...]

5. Cf. Ducrot (apud Henry, 1992:225 e 231), que define a pressuposição por sua inerência ao enunciado (pressuposição referente à significação) e à enunciação (pressuposição como ato de linguagem, realizado na enunciação e, eventualmente, marcado no enunciado). 
Observamos nos dados acima que, ao enunciar, o discurso do sujeito dá abertura a outros sentidos que não os impostos pelo discurso do Direito. O sentido passa por um deslocamento, dando lugar à deriva, ao deslize no depoimento de (TA). Embora exista busca de estabilidade nos sentidos das falas em audiência, durante a composição respectivo termo pelo juiz (J) na tentativa de bloquear o movimento significante e tentar manter estável o sentido, este desliza.

Tomamos o sujeito como, ao mesmo tempo, constituído pela linguagem e por ela afetado; como alguém que não nasce, mas se constitui no campo da linguagem (Elia, 2004). Nossa análise parte, não da noção de sujeito cartesiano, senhor de seus atos e de vontade livre, mas da concepção de sujeito clivado, assujeitado, submetido ao inconsciente e às condições histórico-sociais (Pêcheux, 1988, 2002; Tfouni, 2005), de um sujeito que se constitui junto com o sentido.

No decorrer da audiência são construídas narrativas a respeito de um fato, que colocam o ponto de vista de cada um dos sujeitos, do autor, do réu ou da testemunha. Essas narrativas são retomadas pelo sujeito que ocupa a posição de juiz (J), que, por meio de seus recortes, as coloca dentro de determinados limites impostos pelo discurso do Direito. É, este último, a base sobre a qual o sujeito juiz $^{6}$ transforma narrativas com origem em atividade linguageira e em conhecimento do senso comum em narrativas enquadradas pelo discurso do Direito. (TA), no recorte acima, tem um discurso segundo as formações imaginárias (FI) (Pêcheux, 1988) daquilo que o discurso do Direito qualifica como "depoente", encaixado dentro de um "certo número de valores e de palavras-chaves" (Chemama, 2002:245). Na substituição da fala do depoente pela fala do juiz ocorre o que Orlandi (2003:244) denomina "forma da mistificação", em que a subsunção de uma voz pela outra, "como se" se distingue do "faz de conta", pois, explica a autora, este último "se constitui na relação com o imaginário", e o "como se" se relaciona ao simbólico,

6. Sujeito do direito, conforme explicado anteriormente, pois ele tem o conhecimento da lei. 
com o "domínio das instituições", em que a "fala é ritualizada, dada de antemão" (op. cit.: 247).

Os recortes da fala de (TA) lidos e comparados ao recorte do termo ditado pelo juiz, permitem observar que este último traz um sentido diverso daquele relatado pela testemunha (TA). Houve dispersão no relato dela e, também, associação livre "ele morou lá um ano ... um ano de:: ... sem pagar aluguel sem pagar condomínio e que foi movida uma ação de despejo contra ele e ele saiu deixou danos no imóvel”. Já, no ditado do juiz à escrevente, o depoente (TA) é colocado como enunciador de um discurso com causa e efeito: "Lembra-se que o imóvel não foi devolvido nas mesmas condições em que foi locado, já que o locatário não fez a pintura geral nem a limpeza”. É importante, neste momento, estranhar as expressões "lembra-se", "já que" e, também o fato de o juiz (J) colocar o depoente (TA) como sujeito dessa enunciação. Os enunciados, tanto de (TA) quanto de (J), remetem aos mesmos fatos, porém não constroem as mesmas significações. O sujeito do direito emerge quando o sujeito-juiz (J) enuncia "corretamente" em nome do sujeito-depoente (TA) sendo, este último, estranho à "univocidade lógica” da lei (Pêcheux, 2002:43).

No funcionamento da audiência que acabamos de demonstrar podem ser percebidos atos do sujeito-juiz (J) no intuito de impedir interpretações do sujeito-depoente (TA). Há, nesse momento uma "sobre-interpretação" (Pêcheux, 2002:45) feita pelo juiz (J), que organiza as falas de (TA) "ao modo de uma rede de paradigmas" (op. cit.: 46). Tomando como fundamento da produção de linguagem a relação entre os processos parafrástico ("retorno constante a um mesmo espaço dizível”) e polissêmico ("deslocamento, ruptura, emergência do diferente, da multiplicidade dos sentidos”), podemos afirmar, com Serrani (1993:16 e 23, grifos meus), que a paráfrase, no discurso do Direito, pode ser concebida como "ressonância interdiscursiva de significação que tende a construir a realidade (imaginária) de um sentido", pois é esse mesmo discurso do Direito que define as condições de possibilidade dos enunciados.

As materialidades discursivas dos recortes mencionados implicam um ritual ideológico do discurso do Direito que trabalha o 
sentido das falas do sujeito-depoente (TA), nelas insere um sentido e dá uma única direção ideológica. A retomada, feita pelo sujeitojuiz (J), não é neutra; há superposição de falas no enunciado do sujeito-juiz (J), que, por sua vez, traz outra situação enunciativa: a de coesão de sentido em lugar de dispersão. O juiz (J), ao fazer seu ditado parafraseando o depoente (TA), funde a voz deste com a sua, incorporando-a: "a paráfrase é um discurso sem voz, pois quem está falando está falando o que o outro já disse [...] é uma máscara que se identifica totalmente com a voz que fala atrás de si" (Sant'Anna, 1985:29). A paráfrase é "o outro no mesmo" (Serrani, 1993:29). Há algo que vem regulamentar um percurso do olhar, que faz o discurso "entrar [...] na categoria do mesmo" e rejeitar "como desvios do olhar, todas as zonas de instabilidade, de dispersão, de contradição" (Courtine, 2006:25). O discurso do Direito adquire uma "estrutura, uma ordem de significado" (White, 1991:9), um valor jurídico, valor de prova, somente depois de se tornar uma narrativa escrita do juiz.

Ao lado da constituição do sujeito do direito (sujeito do enunciado, da lei), na cadeia discursiva, há, também, a constituição do sujeito jurídico durante a enunciação feita em audiência. $\mathrm{O}$ discurso do Direito, científico e racionalista traz consigo o recalque, o silenciamento, de modo a colocar o discurso jurídico "como resíduo" (Tfouni, 2008). Esse "objeto recalcado" retorna sob a concepção de um sujeito-falante "que seria a fonte e a origem do dizer, colocando o inconsciente (ideologia e desejo) como pré-condição para que esse dizer se concretize" (op. cit.). Compreendemos o discurso jurídico como discurso narrativo, lugar onde se instala a subjetividade, o modo pelo qual o sujeito organiza sua simbolização particular (Tfouni, 2010a). Denominamos, portanto, sujeito jurídico aquele que emerge nos depoimentos narrados e transcritos e nas sentenças que escapam ao modelo imposto pela lei.

A narrativa do sujeito-juiz, sujeito do direito, traz um "discernimento" em relação ao que foi narrado na audiência; pressupõe a "noção de realidade na qual 'verdadeiro' é identificado com 'o real'" (White, 1991:10); tem começo, meio e fim bem delineados, pois 
o sujeito-juiz é aquele que conhece a lei. A desordem e a ausência de enredo nas falas do depoente são frustrantes para o discurso do Direito, que, por sua vez, as remete à significação mítica do discurso do sujeito juiz. O discurso do Direito não pode, por sua natureza, produzir história subjetiva (sujeito jurídico), mas produz a "existência explícita de uma constituição política que é cultuada em ... leis e costumes racionais" (White, 1991:16), ou seja, o discurso do Direito produz o sujeito do direito.

A constituição do sujeito de direito como signo imagem de $a$, segundo a psicanálise lacaniana, se dá na medida em que "a realidade se presta à representação narrativa”, lugar de "conflito entre o desejo e a lei”, na lição de White (1991:17). Para esse autor (idem), onde não há o poder da lei, não existe nem sujeito nem evento narrado. Assim, no discurso do Direito, a historicidade e a narratividade não existiriam se não houvesse sujeito do direito e sujeito jurídico. White (1991) observa que a narratividade "pressupõe a existência de um sistema legal [...] tem a ver com os tópicos da lei, da legalidade, da legitimidade, ou, mais genericamente, da autoridade" (White, 1991:18). O sujeitojuiz, ao fazer recortes nas falas e ditar para o escrevente de sala o que deve ser escrito no termo, enuncia segundo a determinação da lei; sua narrativa, na cadeia discursiva, se apresenta no lugar mais próximo do conceito do sujeito de direito descrito pela lei, ou seja, aquilo que o sujeito-juiz (sujeito do direito) enuncia deve corresponder à previsão legal para sua conduta.

Em sentença ditada ao escrevente de sala, o juiz (J), em outro recorte, em meio a sua decisão pretensamente segundo os moldes do discurso do Direito, pronuncia a seguinte frase: "Até porque...o contrato não é celebrado...para diletantismo dos contratantes". Quando (J) utiliza o operador "até porque" inseriu, em sua fala, um juízo de valor diverso daquele preconizado pela lei, já que a estrutura formal do raciocínio silogístico - que a lei determina para a elaboração da sentença - "não espelha as propriedades básicas da consciência humana" (Luria apud Tfouni, 2005:37). Ao emitir uma apreciação particular na afirmação: "até porque ...", o sujeito do direito - sujeito na posição de juiz, conhecedor da lei - é dividido por seu próprio discurso, 
ocasião em que emerge o sujeito jurídico na enunciação de interesse particular e se contrapõe à qualidade de não contradição do sujeito científico (Orlandi, 1996:92). Esse é um exemplo de que o sujeito é, ao mesmo tempo, "sujeito da ideologia e sujeito do desejo inconsciente e isso tem a ver com o fato de nossos corpos serem atravessados pela linguagem antes de qualquer cogitação” (Henry, 1992:188).

Podemos observar, a esse respeito, que há uma "estratégia alternativa à prática linear escriturística" (cf. Tfouni \& Pereira, 2010) dentro do raciocínio lógico institucionalizado do Poder Judiciário. Essa estratégia escapa ao "rígido esquema de papéis" e ao "fechamento da interpretação" (op. cit.) da estrutura silogística e se caracteriza como "uma resistência à interpelação da formação ideológica dominante" do discurso do Direito. A esse processo Certeau (1999:252, apud Tfouni, 2006:22) dá o nome de "economia escriturística", "uma outra coisa” que é "calada - recalcada, melhor dizendo - mas que no entanto retorna', ... escapando à dominação de uma economia sociocultural [...] ao poder de uma elite e, enfim, ao controle da consciência esclarecida" . Ao estudarmos o sujeito no discurso jurídico, voltamo-nos para " o único sujeito que se deve supor é aquele que a psicanálise define como efeito da linguagem enquanto realização do simbólico” (Henry, 1992: 186). O grande Outro, segundo Lacan, é a matriz simbólica, e se equipara à ação estruturante da linguagem que leva a um hiato entre organismo e corpo (Godoy, 2009).

Quando colocamos lado a lado sujeito de direito, "signo imagem de a" (situando o Estado no lugar do espelho A) (Lacan, 1992:342) e sujeito jurídico, queremos demonstrar que na cadeia discursiva durante uma audiência, ainda que seja um contexto sóciohistórico em que a determinação legal predomina, o sujeito (jurídico ou o sujeito do direito) não é dono de seu dizer. No recorte transcrito acima, o sujeito-juiz (sujeito do direito), conhecedor da lei, sujeito do enunciado desta, é cindido, pois também é sujeito da enunciação e, ao ditar para o escrevente de sala, não se dá conta dessa divisão e traz, em sua fala, valor particular e não o valor universal preconizado pela lei por meio do raciocínio silogístico. 


\section{Considerações finais}

Ao aproximarmos a evidência do sujeito e do sentido, imposta pela ideologia, como sugere Pêcheux (1988), podemos compreender a dificuldade existente no jogo de efeitos ideológicos do discurso do Direito. Quando dissimulamos a "intersubjetividade falante" do sujeito do direito (sujeito-juiz) pudemos observar outro valor em sua enunciação, que não o ditado pela lei; foi possível observar a história se inscrevendo no discurso desse sujeito constituindo o sujeito jurídico em sua enunciação durante uma audiência. Levando em conta o que Elia (2004) ensina sobre o inconsciente psicanalítico, como algo que não é articulável, mas que pode já estar articulado ao nível do inconsciente e da sujeição do sujeito a esse inconsciente que se articula sem seu arbítrio, pudemos observar a produção de atos falhos e lapsos discordantes das características que deveriam estar presentes no sujeito do direito, sujeito do enunciado do termo de audiência ou da sentença.

Nos recortes citados neste estudo, pudemos observar que a fala é determinada de fora da vontade do sujeito (Authier-Revuz, 1990); que o discurso é produto do interdiscurso e o sujeito ignora isso ao crer que é a fonte de seu discurso. O "eu forte", autônomo e livre é uma ilusão que a ciência do Direito produz para o sujeito. A AD (Pêcheux, 1988) e o Letramento (Tfouni, 2005), permitem observar a constituição do sujeito jurídico e do sujeito do direito na materialidade da língua, lugar do equívoco e da falha.

Concluímos nosso estudo propondo que o assujeitamento ideológico (Pêcheux, 1988) e a constituição psicanalítica (Lacan, 1998) do sujeito sejam pensados como coisas que se aproximam nos processos de "imposição-dissimulação" (Pêcheux, 1988) que constituem o sujeito, no que diz respeito à tese em que a ideologia interpela os indivíduos em sujeitos livres, para que livremente se submetam às ordens do Sujeito. Assim, propomos a compreensão do Estado como uma evidência anterior ao sujeito, como uma evidência anterior à luta entre duas forças, como espaço, terreno dessa luta, de modo a produzir-reproduzir sujeitos de direito como "evidências 
naturais" (Pêcheux, 1988). Acreditamos haver diferença entre sujeito de direito e sujeito jurídico. Entendemos que, no "Estado do sujeito de direito", o assujeitamento é do sujeito jurídico. O "sujeito de direito" seria o "signo imagem de a" (Lacan, 1992:342), que o Estado, como "A", no esquema ótico de Lacan ([1960] 1998:653), oferece ao "assujeitamento do sujeito".

Para Pêcheux (1988) a constituição do sentido e a constituição do sujeito juntam-se na figura da interpelação (na qual vinculamos sujeito ideológico e sujeito de direito) e, ao mesmo tempo, fica dissimulada a subordinação-assujeitamento ao grande Outro (Estado) sob a forma da autonomia (estrutura discursiva da forma-sujeito). Pensamos, portanto, a determinação do sujeito pela Lei (Estado) em dois momentos que ocorrem simultaneamente: pela determinação histórica (teoria materialista dos processos discursivos de Pêcheux) e pela determinação constitutiva (em que a libido do eu estaria investida na imagem do Estado como grande Outro, imagem esterilizante, que leva à passagem do $[e u]$ especular para o $[e u]$ social) (Lacan, [1949]1998). A utilização metafórica do esquema ótico completo de Lacan ([1949] [1960] 1998), para dar ao Estado a função de "A", espelho plano, proporciona a formação do sujeito de direito equivalente ao ideal do eu, "como um campo organizado de uma certa maneira no interior do sujeito" (Lacan, 1992). Nessa elaboração do Estado como espelho (A), o sujeito teria sua função preenchida pela imagem de sujeito de direito, à imagem e semelhança do Estado como o grande Outro. Os referenciais do conhecimento especular não são da ordem visual. O sujeito advém do objeto do olhar de um outro.

Nessa nova dimensão de sensibilidade sobre a dimensão política do sujeito distanciamo-nos do fetichismo do Direito, rompemos a lógica convencional do jurídico e trouxemos a possibilidade de observar como opera o inconsciente na determinação do sujeito com a alteridade: "o que diz respeito ao ser, ao ser que se colocaria como absoluto, não é jamais senão a fratura, a rachadura" (Lacan,[1972-1973]1985:20).

Segundo a proposta do continuum do Letramento, de Tfouni $(1992,2005)$, observamos, estabelecidas as diferenças entre discurso do Direito e discurso jurídico, as diferenças conceituais entre sujeito 
jurídico (sujeito da enunciação), sujeito de direito (ideológico e signo imagem de a), e sujeito do direito (sujeito do enunciado; sujeito que ocupa essa posição por ser conhecedor e aplicador da lei).Essas noções são de difícil percepção; podem, no entanto, ser observadas no funcionamento discursivo, na relação enunciado/formulação (Lagazzi, 1988:56), pois ali há “uma ilusão que, no interior do discurso, pode ocupar diferentes posições” (Lagazzi, 1988:57). Essa distinção conceitual nos permite observar o sujeito clivado na aplicação da lei.

\section{Referências bibliográficas}

ACHARD, Pierre et al., Papel da memória, Campinas: Ed. Pontes, 1999

ALTHUSSER, L., Ideologia e Aparelhos Ideológicos do Estado, In: Um mapa da ideologia, Slavoj Zizek org., Rio de Janeiro: Contraponto, p. 105-142, 1999

AUTHIER-REVUZ, J., Heterogeneidade(s) enunciativa(s), In: Cadernos de Estudos Lingüísticos, Campinas: UNICAMP/IEL, jul.-dez., p. 26-36, 1990.

BOURDIEU, P., O poder simbólico, $2^{\mathrm{a}}$ Ed., Rio de Janeiro: Berthand Brasil, 1998.

BRASIL, Lei de Introdução ao Código Civil (LICC), Decreto-Lei n 4657 de 04.09.1942, org. Theotônio Negrão, José Roberto Ferreira Gouvêa, São Paulo: Saraiva, 2007.

BRASIL, Código de Processo Civil, Lei 5869, de 11.01.1973, In NEGRÃO, T. e GOUVÊA, J., 39ª Ed., São Paulo: Saraiva, 2007.

BRASIL, Constituição da República Federativa do Brasil, promulgada em 05.10.1988, org. Yussef Said Cahali, 5ª ed., São Paulo: RT, 2003.

CERTEAU, M., A invenção do cotidiano: artes de fazer; Petrópolis, RJ: Vozes, 1994.

CHEMAMA, R. Elementos lacanianos para uma psicanálise no cotidiano, Porto Alegre: CMC Editora, 2002.

CINTRA, A.C., GRINOVERA. e DINAMARCO C., Teoria Geral do Processo, $3^{\text {a }}$ ed, São Paulo: RT, 1981. 
COURTINE, J., Metamorfoses do discurso político: as derivas da fala pública, trad. Nilton Milanez, Carlos Piovezzani Filho, São Carlos: Ed. Claraluz, 2006. DINAMARCO, C., Fundamentos do Processo Civil Moderno, tomo I, São Paulo: Malheiros Editores Ltda, 2000.

DOR, J., Introdução à leitura de Lacan: o inconsciente estruturado como linguagem, Porto Alegre: Ed. Artes Médicas, p.139-147, 1989.

ELIA, L. O conceito de sujeito, Rio de Janeiro: Ed. Jorge Zahar , 2004.

FREUD, S., Totem e tabu. In: Obras psicológicas completas, trad. Jayme Salomão. Rio de Janeiro: Imago, vol. XIII, p. 21-162, 1996.

GINZBURG, Carlo. Mitos, emblemas, sinais: morfologia e história. São Paulo: Ed. Companhia das Letras, 1989.

GODOY, H., Saber e conhecimento. Acesso em 30 de agosto de 2009. Disponível em http://www.escolaletrafreudiana.com.br/pagina.php?id=4952 GUIMARÃES, E. Semântica do acontecimento: um estudo enunciativo da designação. Campinas: Pontes, 2002.

HAROCHE, C. Fazer dizer, querer dizer. São Paulo: Ed. Hucitec, 1992.

HENRY, P. A ferramenta imperfeita: língua, sujeito e discurso, trad. Maria Fausta P. de Castro, Campinas: Ed da UNICAMP, 1992.

LACAN, J., Seminário I. Os escritos técnicos de Freud, (1953-1954). Rio de Janeiro: Jorge Zahar, 1986.

. O seminário, livro 2: o eu na teoria de Freud e na técnica da psicanálise (1954-1955). Rio de Janeiro: Jorge Zahar, 1987.

. A instância da letra no inconsciente ou a razão desde Freud (1957). In: Escritos. Rio de Janeiro: Jorge Zahar, 1998.

. O estádio do espelho como formador da função do eu (1949), In: Escritos. Rio de Janeiro: Jorge Zahar, p. 96, 1998.

. Observação sobre o relatório de Daniel Lagache: "Psicanálise e estrutura da personalidade" (1960). In: Escrito., Rio de Janeiro: Jorge Zahar, p. 653, 1998.

. O seminário, livro 20: mais ainda, (1972-1973), Rio de Janeiro: Jorge Zaharo, 1985.

. O seminário, livro 8: a transferência, trad. Dulce Duque Estrada, Rio de Janeiro: Jorge Zahar, 1992. 
LAGAZZI, S. O juridismo marcando as palavras: uma análise do discurso cotidiano. Dissertação de Mestrado inédita.Programa de Pós-Graduação em Lingüística, IEL-UNICAMP, 1987.

LURIA, A. R. Cognitive Development: its cultural and social foundations. Cambridge: Harvard University Press, 1977.

MELENOTTE, G. Sustancias del imaginario, trad. de Silvia Pasternac, México: Epeele, 2006.

LEGENDRE, P. Jouir du povoir (Traité de bureaucratie patriote)., Paris: Éd. Minuit, 1976.

MIAILle, M. Uma Introdução Crítica ao Direito, trad. Ana Prata, Lisboa: Moraes Editores, 1979.

MILNER, J.C. O amor da língua. Porto Alegre: Artes Médicas, 1987.

ORLANDI, E. Interpretação, autoria, leitura e efeitos do trabalho simbólico. Petrópolis, RJ: Vozes, 1996.

- A linguagem e seu funcionamento: as formas do discurso. Campinas, SP: Pontes, 2003.

- Interpretação, autoria, leitura e efeitos do trabalho simbólico, $4^{\mathrm{a}}$ ed. Campinas: Ed. Pontes, 2004.

PÊCHEUX, M. Semântica e discurso: uma crítica à afirmação do óbvio. Campinas: Ed. Unicamp, 1988.

. Por uma análise automática do discurso. Campinas: Ed. Unicamp, 1990.

O Discurso: estrutura ou acontecimento. Campinas: Ed. Pontes, 2002. PHILIPPI, J. Observações sobre as possibilidades de redifinição da categoria Sujeito de Direito. Acesso em 12 de março de 2010. Disponível em http://www. buscalegis.ufsc.br/revistas/index.php/sequencia/article/viewFile/1201/1197 ROSA, A. Decisão no Processo Penal como Bricolage de Significantes. Tese de Doutorado inédita. Programa de Pós-Graduação em Direito, Universidade Federal do Paraná.

Acesso em 11 de março de 2010. Disponível em http://dspace.c3sl.ufpr. br/dspace/bitstream/1884/1203/1/0\%20\%202004\%20Alexandre\%20 Rosa\%204.pdfx

SANT’ANNA, A.R. Paródia, Paráfrase \& Cia, 2a ed., São Paulo: Ed. Ática, 1985. 
SERRANI, S. A Linguagem na Pesquisa Sociocultural: um estudo da repetição na diversidade. Campinas: Ed. da UNICAMP, 1993.

SILVA, D. P. Vocabulário Jurídico, 10ª . ed., Rio de Janeiro: Editora Forense, 1987.

TFOUNI, L. Letramento e Analfabetismo. Tese de livre-docência, FFCLRP USP, Ribeirão Preto, 1992.

- Letramento e alfabetização, 6ª ed. São Paulo: Ed. Cortez, 2005.

- Mensagem e poesia. A atualidade de Saussure e Jakobson, ou sobre a verdade do sujeito (e do sentido) em deriva. In: Gaspar, N. M. \& Romão, L. M. S. (orgs.) Discurso e texto: multiplicidade de sentidos na Ciência da Informação. São Carlos: EDUFSCAR, 2008.

TFOUNI, L. \& CARREIRA A. O sujeito submetido à linguagem. In: Revista Investigações da Universidade Federal de Pernambuco, vol. 20, n. 2, jul., Pernambuco, 2007.

WHITE, H., O valor da narratividade na representação da realidade, trad. José Luis Jobin, Niterói: Instituto de Letras da UFF, 1991.

ZARKA,Y. Jacques Lacan. Psicoanálisis y política. Buenos Aires: Nueva Visión, 2004.

Recebido em: maio de 2010 Aprovado em: setembro de 2010 di_motta61@yahoo.com.br lvtfouni@usp.br 